Research Article

\section{Gynaecological malignancies after breast cancer diagnosis: A population- based study}

\author{
Maria Pilar Barretina-Ginesta1, Jaume Galceran ${ }^{2,3 *}$, Helena Pla1, \\ Cristina Meléndez ${ }^{4}$, Anna Carbo Bague ${ }^{1}$, Alberto Ameijide ${ }^{2,3}$, \\ Marià Carulla ${ }^{2,3}$, Jordi Barretina ${ }^{6}$, Angel Izquierdo $0^{1,5,6}$ and Rafael \\ Marcos-Gragera ${ }^{5-8}$
}

\author{
${ }^{1}$ Medical Oncology Department, Catalan Institute of Oncology (ICO), Girona; Girona Biomedical \\ Research Institute (IDIBGI); Department of Medical Sciences, Medical School University of Girona \\ (UdG), Spain \\ ${ }^{2}$ Tarragona Cancer Registry, Foundation Society for Cancer Research and Prevention (FUNCA), \\ Reus, Spain \\ ${ }^{3}$ Pere Virgili Health Research Institute (IISPV), Reus, Spain \\ ${ }^{4}$ Pathology Department, Hospital Universitari de Girona Dr. Josep Trueta, Girona, Spain \\ ${ }^{5}$ Epidemiology Unit and Girona Cancer Registry, Oncology Coordination Plan, Department of \\ Health, Autonomous Government of Catalonia, Catalan Institute of Oncology (ICO), Girona, Spain. \\ ${ }^{6}$ Descriptive Epidemiology, Genetics and Cancer Prevention Group, Biomedical Research Institute \\ (IDIBGI), Girona, Spain. \\ ${ }^{7}$ Girona University, Girona, Spain \\ ${ }^{8}$ Consortium for Biomedical Research in Epidemiology \& Public Health (CIBERESP), Carlos III \\ Institute of Health. Av/Monforte de Lemos, 5, 28029, Madrid, Spain
}

\begin{abstract}
More Information
*Address for Correspondence: Jaume Galceran MD, PhD, Tarragona Cancer Registry, Foundation Society for Cancer Research and Prevention, (FUNCA), Pere Virgili Health Research Institute (IISPV), Sant Joan de Reus University Hospital, Av. del Dr. Josep Laporte, 2, 43204 Reus, Spain, Tel: 9773103 00;

Email: rmarcos@iconcologia.net
\end{abstract}

Submitted: 24 October 2019

Approved: 30 October 2019

Published: 31 October 2019

How to cite this article: Barretina-Ginesta MP, Galceran J, Pla H, Meléndez C, Bague AC, et al. Gynaecological malignancies after breast cancer diagnosis: A population-based study. Clin J Obstet Gynaecol. 2019; 2: 113-118.

DOI: dx.doi.org/10.29328/journal.cjog.1001031

Copyright: @ 2019 Barretina-Ginesta MP, et al. This is an open access article distributed under the Creative Commons Attribution License, which permits unrestricted use, distribution, and reproduction in any medium, provided the original work is properly cited.

Keywords: Breast cancer; Gynaecological malignancies; Second primary cancer; Standardized incidence ratio

Check for updates

\title{
Abstract
}

Background: Breast cancer (BC) is one of the most prevalent malignancies. $\mathrm{BC}$ survivors have higher risk of second primary cancers than the general population. There is an increased interest in $\mathrm{BC}$ survivor management, including the prevention of these second cancers. The aim of this study was to assess the risk of gynaecological malignancy (GM) as second neoplasm among BC patients in our population.

Methods: Patients with invasive BC diagnosed from 1980 to 2014 included in the Girona Cancer Registry were included. The incidence of second GM in these patients was compared to those in the general population. Second primary cancer was stated as a tumour diagnosed after 2 months from the BC diagnosis. Standardized incidence ratios (SIR) and absolute excess of risk (AER) were calculated.

Results: 9,717 patients were diagnosed with invasive BC during this period, with a median age at diagnosis of 61 years, and a median follow-up of 7.9 years. 117 of them developed a second GM. By tumour type, the only statistically significant higher SIR was observed for corpus uteri cancer (SIR:2.28 95\% Cl 1.82-2.83; AER:6.43 95\% Cl 4.13-9.14). After reviewing the histology of the corpus uteri cancer cases, we found that 71.4\% were type I (endometrioid adenocarcinoma), $15.5 \%$ type II (serous adenocarcinomas and clear cell carcinomas), $10.7 \%$ carcinosarcomas, $2.4 \%$ sarcomas and there were no unspecified malignant neoplasms.

Conclusion: $\mathrm{BC}$ survivors have an increased risk of corpus uteri cancer, with an increase in unfavourable histologies compared to the general population. Lifelong primary and secondary prevention interventions should be recommended for these patients.

\section{Introduction}

Breast cancer (BC) is the most common diagnosed cancer and the leading cause of cancer death among women worldwide. It has been estimated that 2.1 million of new cases will be diagnosed in 2018. Based on rates from the GLOBOCAN 2018, 5.03\% (one in 20) of women born today will be diagnosed with $\mathrm{BC}$ at some point during their lifetime [1].

In Catalonia, there has been a change in the epidemiology of $\mathrm{BC}$ during the last 20 years. An increase of the incidence has been observed, achieving a crude rate of 118.6 cases per 100,000 women per year in 2015 , but there has been a significant decrease in mortality since 1990 [2]. In Girona province, women diagnosed during the 2010-2014 period had a 5-years relative survival of $83.9 \%$ [3].

Although BC is the leading cause of death by cancer in women, advances in screening [4], diagnosis and therapeutic 
approaches have improved its survival rate in the past decades. In light of this increased survival, the group of $\mathrm{BC}$ patients is exposed to a long-term risk of developing second malignancies. This second neoplasms are suggested to be related with the potential side effects of the treatment received (chemotherapy, radiotherapy and hormone therapy) [5], but also with shared risk factors with other malignancies [6]. In recent decades, there is an emerging awareness about survivors and their life quality. One of the main concerns is the study and application of health interventions in this group of patients to reduce the exposure to risk factors that lead to a second primary malignancy and to assure an early diagnosis in cases when a second cancer appears [7].

Many aetiological factors described for BC are also related to other types of cancer. There are non-modifiable risk factors such as gender, age or race [8]. Furthermore, early aged BC susceptibility genes like BRCA1 and BRCA2 can increase the risk of gynaecological malignancies (GM) such as ovarian and fallopian tube carcinomas [9], while PTEN and P53 mutations are also related with ovarian and uterine (endometrial) cancers [10]. Modifiable, lifestyle-related risk factors for BC such as diet, obesity and hormone therapy after menopause are also risk factors described for endometrial cancer [6].

Several cancer registry-based studies and series that describe the incidence of second neoplasms among $\mathrm{BC}$ survivors have been published. Most of them reported an overall excess risk of about 20\%-30\% for second primary cancers (not including contralateral BC). The most consistent findings have been reported for sites like endometrium, ovary, thyroid gland, stomach, soft tissue sarcomas, blood and lung [11-16]. In addition to this, BC patients treated with tamoxifen presented an increased risk of endometrial cancer, and particularly those rare tumour types associated with poor prognosis [17].

On the other hand, some studies about women diagnosed with GM suggest that being previously diagnosed with BC could act as a risk factor to develop such GM [18]. Consequently, this association between breast and gynaecological cancers may indicate the need to establish specific guidelines for the diagnosis, treatment and follow-up of BC patients.

Based on the hypothesis that BC patients have an increased risk to develop GM, which may be related with shared risk factors and treatment side effects, the aims of this study were: 1 ) to analyse the incidence of second primary GM in a cohort of $\mathrm{BC}$ patients, 2) to assess this risk with the risk of developing a GM in the general population, in order to determine the excess risk in these patients, and 3) to compare the percent distribution of corpus uteri cancer histologies after BC with those that present the patients with corpus uteri cancer as a first primary tumour.

\section{Material and Methods}

In this retrospective cohort study, we used data from the
Girona Cancer Registry (GCR), a population-based cancer registry in the northeast of Spain that covers the Girona province (with a population of 756,156 people according to the census of 2014, source: Catalan National Institute of Statistics, IDESCAT). The GCR was established in 1980 as a monographic population-based registry for gynaecological and breast cancers. Since 1994 it includes information about all types of cancer. Its main information sources are the records of regional and community hospitals, the haematology and pathology departments, and death certificates.

Our study cohort included all women, aged 18 or more, who had a diagnosis of an invasive BC (codes from C50.0 to C50.9 of the $10^{\text {th }}$ revision of the International Classification of Diseases ICD-10) over the period of 1980-2014. This cohort was followed until December 31 31 , 2014 in order to find all second primary invasive GM except contralateral BC. GM corresponds to codes C51 to C57 for malignant neoplasms of the vulva, vagina, cervix uteri, corpus uteri, uterus not otherwise specified (NOS), ovary and unspecified female genital organs. The inclusion or exclusion criteria of tumours as second primary cancers were defined following the IARCIACR recommendations for the definition of multiple primary cancers.

The observed incidence of second GM in our cohort of patients was compared against the expected incidence of these tumours in the reference population. Standardized Incidence Ratios (SIR) were calculated dividing the observed second GM among the BC patients cohort by the expected number of GM based on population rates. In order to validate the study's hypothesis, it was assumed that the observed number of second GM cases followed a Poisson distribution. All the analyses were computed using $\mathrm{R}$ software. The observed number of cases included all second GM diagnosed in the patient's cohort.

To estimate the expected number of cancers, the 5-year age group, period (1980-1984, 1985-1989, 1990-1994, 1995-1999, 2000-2004, 2005-2009, and 2010-2014) and site-specific incidence rates (extracted from the GCR) were multiplied by the number of accumulated person-years at risk (PYO).

The PYO was defined as the number of years from the date of first BC diagnosis to date of second GM, date of death or end of follow-up (December 31 ${ }^{\text {st }}, 2014$ ), whichever date came first, and was calculated using the person-years and mortality computation programme (PAMCOMP).

The excess absolute risks (EAR) beyond the expected ones were calculated subtracting the expected number of subsequent cancers from the observed number of cases of cancer and dividing the difference by the observed personyears and expressing the number of cases in excess or deficit by 100,000 person-years. 
The SIRs were evaluated by each GM tumor type and all GM (C51-C57) using the International Classification of Diseases, 10th edition (ICD-10). The first two months after the first cancer diagnosis were considered as a synchronous period and the SIRs were computed both excluding and including the observed and the expected cases during this period.

With the aim of comparing corpus uteri cancer histologies after breast cancer with those of corpus uteri cancer as first primary tumors, five different histological classification groups of corpus uteri cancer were used in this study (Table 1). The classification used follows the WHO Classification of tumours of the corpus uteri. The five groups were: 1 ) epithelial tumours type I (endometrial carcinoma, adenocarcinoma NOS and adenocarcinoma with squamous differentiation), 2) epithelial tumours type II (serous/papillary serous and mixed

Table 1: Histological classification of tumours of the corpus uteri. ICDO3 Histological Classification

\section{Type I, Endometrioid adenocarcinomas}

\begin{tabular}{|l|l|c|}
\hline & 8070 & Squamous cell carcinoma, NOS \\
\hline 8071 & Squamous cell carcinoma, keratinizing, NOS \\
\hline 8140 & Adenocarcinoma, NOS \\
\hline 8211 & Carcinoma tubular \\
\hline 8262 & Villous adenocarcinoma \\
\hline 8380 & Endometrioid adenocarcinoma \\
\hline 8383 & Endometrioid adenocarcinoma, ciliated cell variant \\
\hline 8384 & Adenocarcinoma, endocervical type \\
\hline 8480 & Mucinous adenocarcinoma \\
\hline 8481 & Mucin-producing adenocarcinoma \\
\hline & 8560 & Adenosquamous carcinoma \\
\hline 8570 & Adenocarcinoma with squamous metaplasia \\
\hline 8934 & Carcinofibroma \\
\hline
\end{tabular}

2 Type II, Serous adenocarcinomas and clear cell carcinomas

\begin{tabular}{|c|c|c|c|}
\hline & & 8020 & Carcinoma, undifferentiated, NOS \\
\hline & & 8260 & Papillary adenocarcinoma, NOS \\
\hline & & 8310 & Clear cell adenocarcinoma, NOS \\
\hline & & 8323 & Mixed cell adenocarcinoma \\
\hline & & 8441 & Serous cystadenocarcinoma, NOS \\
\hline & & 8460 & Papillary serous cystadenocarcinoma (C56.9) \\
\hline & & 8461 & Serous surface papillary carcinoma (C56.9) \\
\hline \multirow[t]{9}{*}{3} & Mesenchymal tumours & & \\
\hline & & 8800 & Sarcoma, NOS \\
\hline & & 8890 & Leiomyosarcoma \\
\hline & & 8891 & Leiomyosarcoma, epithelioid variant \\
\hline & & 8896 & Leiomyosarcoma, myxoid variant \\
\hline & & 8930 & Undifferentiated endometrial sarcoma \\
\hline & & 8931 & Endometrial stromal sarcoma, low grade \\
\hline & & 8935 & Stromal sarcoma, NOS \\
\hline & & 9110 & Mesonephroma, malignant \\
\hline \multirow[t]{5}{*}{4} & Mixed epithelial and $\mathrm{me}$ & senchy & ial tumours \\
\hline & & 8933 & Adenosarcoma \\
\hline & & 8950 & Mullerian mixed tumour (C54._) \\
\hline & & 8951 & Mesodermal mixed tumour \\
\hline & & 8980 & Carcinosarcoma \\
\hline \multirow[t]{5}{*}{5} & Others & & \\
\hline & & 8010 & Carcinoma, NOS \\
\hline & & 8012 & Large cell carcinoma, NOS \\
\hline & & 8030 & Giant cell and spindle cell carcinoma \\
\hline & & 8230 & Solid carcinoma, NOS \\
\hline
\end{tabular}

cell adenocarcinoma) following the indications of different endometrial cancers reports [19], 3) mesenchymal tumours, 4) mixed epithelial and mesenchymal tumours and 5) others tumours of the uterine corpus. All corpus uteri cancer with an unspecified histological diagnosis were reviewed in order to include each of them in one of these five histological groups. Furthermore, all histological samples of cases classified as carcinosarcoma were reviewed by a pathologist to validate the diagnosis. Then, the frequency and distribution of histological groups by first or second corpus uteri cancer was described and a Chi-squared test for statistical inference was performed. A missing completely at random pattern was assumed and thus a complete case analysis was performed.

\section{Results}

The study included 9,717 cases of BC diagnosed between 1980 and 2014 with one month or more of follow-up yielding 76,764 PYO (Table 2). The median age at diagnosis of primary $\mathrm{BC}$ was 61 (range $=18-102$ ) years. A total of 117 second primary GM were diagnosed in our cohort ( $1.20 \%$ of patients) versus 76.8 expected in the reference population (SIR 1.52; 95\% CI 1.26-1.83, EAR 5.41/100,000 person-years) (Table $3)$. The median age among patients diagnosed with a second GM after BC was 67.5 (range $=34-89$ ) years, with a median duration between the diagnosis of $\mathrm{BC}$ and the diagnosis of the GM of 5.88 (range $=0-23$ ) years. The mean follow-up time was 7.90 (range $=0-26$ ) years.

The most common observed second GM was corpus uteri cancer, with 84 cases diagnosed versus 37.21 expected (SIR 2.28; 95\% CI 1.82-2.83; AER 6.43/100,000 PYO). We also

Table 2: Descriptive characteristics of the Girona breast cancer cohort.

\begin{tabular}{|c|c|c|}
\hline & $\mathbf{N}$ & $(\%)$ \\
\hline Breast cancer cohort patients $(1980-2014)$ & 9,717 & 100 \\
\hline \multicolumn{3}{|l|}{ Age at diagnosis of breast cancer } \\
\hline Mean & 61.05 & - \\
\hline Median & 61 & - \\
\hline$<50 y$ & 2,503 & $25.8 \%$ \\
\hline$\geq 50 y$ & 7,250 & $74.6 \%$ \\
\hline \multicolumn{3}{|l|}{ Years of breast cancer diagnosis } \\
\hline 1980-1984 & 672 & $6.9 \%$ \\
\hline 1985-1989 & 914 & $9.4 \%$ \\
\hline 1990-1994 & 1,143 & $11.8 \%$ \\
\hline 1995-1999 & 1,393 & $14.3 \%$ \\
\hline $2000-2004$ & 1,683 & $17.3 \%$ \\
\hline $2005-2009$ & 1,832 & $18.9 \%$ \\
\hline $2010-2014$ & 2,080 & $21.4 \%$ \\
\hline \multicolumn{3}{|l|}{ Follow-up time (years) } \\
\hline Mean & $7.9 \mathrm{y}$ & - \\
\hline Median & 5.88 y & - \\
\hline \multicolumn{3}{|c|}{ Interval between diagnosis of breast and second gynaecological malignancies } \\
\hline$<1 \mathrm{y}$ & 1,260 & $13.0 \%$ \\
\hline $1-4$ y & 3,089 & $31.8 \%$ \\
\hline $5-9$ y & 2,367 & $24.4 \%$ \\
\hline $10-14 y$ & 1,422 & $14.6 \%$ \\
\hline$>15 y$ & 1,579 & $16.2 \%$ \\
\hline
\end{tabular}


observed 3 patients diagnosed with vulva cancer versus 5.67 expected (SIR 0.53; 95\%CI 0.10-1.57; AER -0.36/100,000 PYO); 1 case of vaginal cancer versus 0.85 expected (SIR 1.17; 95\% CI 0.00-6.73; AER 0.02/100,000 PY0); 5 cases of cervical cancer versus 9.84 expected (SIR 0.51; 95\% CI 0.16-1.20; AER -0.65/100,000 PYO); 19 cases of ovarian cancer versus 19.89 expected (SIR 0.96; 95\% CI 0.57-1.49; AER -0.12/100,000 PYO) and 5 cases of other and unspecified female genital organs cancers versus 1.46 expected (SIR 2.73; 95\% CI 0.717.07; EAR 0.34/100,000 PYO) (Table 3).

Between $1^{\text {st } J a n u a r y ~} 1980$ and 31 ${ }^{\text {st }}$ December 2014, 1,661 women were diagnosed with corpus uteri cancer in the Girona province. Table 4 shows the distribution of the morphologies according to the five groups. Most women had type I adenocarcinomas $(84.5 \%)$ while the $7.5 \%$ of them had tpye II adenocarcinomas, 3.6\% mixed epithelial and mesenchymal tumours, $3.4 \%$ mesenchymal tumours and $0.7 \%$ others. The distribution of histologies of corpus uteri cancer after $\mathrm{BC}$ was different from those of corpus uteri cancer as first primary tumour. Among the 84 cases of corpus uteri cancer after BC, $71.8 \%$ were type I adenocarcinoma, $15.3 \%$ type II adenocarcinoma, $10.6 \%$ mixed epithelial and mesenchymal tumours, $2.4 \%$ mesenchymal tumours and there were no cases of unspecified malignant neoplasms. Despite the lack of information on the histologic subtype of approximately $20 \%$ of the samples, we observed a higher proportion of high-risk histologies (adenocarcinoma type II and Mixed epithelial and mesenchymal tumours) among corpus uteri cancer which were second neoplasm.

Table 3: Age-standardized incidence ratios (SIR) and excess absolute risk (EAR) of gynaecological malignancies after breast cancer (excluded first 60 days after breast cancer diagnosis) from 1980 to 2014 in Girona.

\begin{tabular}{|c|c|c|c|c|c|c|}
\hline $\begin{array}{l}\text { Second gynaecological } \\
\text { malignancies }\end{array}$ & OBS & EXP & SIR & $95 \% \mathrm{CI}$ (SIR) & EAR & $\begin{array}{l}95 \% \mathrm{Cl} \\
\text { (EAR) }\end{array}$ \\
\hline Vulva (C51) & 3 & 5.67 & 0.53 & $(0.10-1.57)$ & -0.36 & $(-0.69-0.43)$ \\
\hline Vagina (C52) & 1 & 0.85 & 1.17 & $(0.00-6.73)$ & 0.02 & $(-0.11-0.66)$ \\
\hline Cervix uteri (C53) & 5 & 9.84 & 0.51 & $(0.16-1.20)$ & -0.65 & $(-1.11-0.26)$ \\
\hline Corpus uteri (C54) & 84 & 37.21 & $2.28 *$ & $(1.82-2.83)^{\star}$ & 6.43 & $(4.13-9.14)^{\star}$ \\
\hline Uterus, unspecified (C55) & 0 & 1.87 & 0.00 & $(0.00-2.09)$ & -0.25 & $(-0.25-0.28)$ \\
\hline Ovary (C56) & 19 & 19.89 & 0.96 & $(0.57-1.49)$ & -0.12 & $(-1.14-1.32)$ \\
\hline $\begin{array}{l}\text { Other and Unspecified female } \\
\text { genital organs (C57) }\end{array}$ & 5 & 1.46 & 2.73 & $(0.71-7.07)$ & 0.34 & $(-0.06-1.19)$ \\
\hline Total (C51-C58) & 117 & 76.8 & $1.52^{*}$ & $(1.26-1.83)^{\star}$ & 5.41 & $(2.69-8.53)^{\star}$ \\
\hline
\end{tabular}

Table 4: Comparison of the histological group distribution according to the 2014 WHO classification between corpus uteri cancer as first tumour and corpus uteri cancer after first primary breast cancer. Girona, 1980-2014.

\begin{tabular}{|c|c|c|c|c|c|c|c|}
\hline \multirow{2}{*}{ Histological group } & \multicolumn{2}{c}{$\begin{array}{c}\text { Corpus uteri } \\
\text { Total }\end{array}$} & \multicolumn{2}{c|}{$\begin{array}{c}\text { Corpus uteri } \\
\mathbf{1}^{\text {st }}\end{array}$} & \multicolumn{2}{c|}{$\begin{array}{c}\text { Corpus uteri } \\
2^{\text {nd }}\end{array}$} & p - value* \\
\cline { 2 - 9 } & $\mathbf{N}$ & $\%$ & $\mathbf{N}$ & $\%$ & $\mathbf{N}$ & $\%$ & \\
\hline Adenocarcinomas type I & 1403 & $84.5 \%$ & 1343 & $85.2 \%$ & 60 & $71.8 \%$ & $p<0.001$ \\
\hline Adenocarcinomas type II & 124 & $7.5 \%$ & 111 & $7.0 \%$ & 13 & $15.3 \%$ & $p=0.008$ \\
\hline $\begin{array}{c}\text { Mixed epithelial and } \\
\text { mesenchymal tumours }\end{array}$ & 60 & $3.6 \%$ & 51 & $3.2 \%$ & 9 & $10.6 \%$ & $p=0.002$ \\
\hline Mesenchymal tumours & 63 & $3.8 \%$ & 61 & $3.9 \%$ & 2 & $2.4 \%$ & $p=0.37$ \\
\hline Others & 11 & $0.7 \%$ & 11 & $0.7 \%$ & 0 & $0.0 \%$ & $p=0.56$ \\
\hline Total & 1661 & $100.0 \%$ & 1577 & $100.0 \%$ & 84 & $100.0 \%$ & \\
\hline
\end{tabular}

\section{Discussion}

The number of BC survivors has increased due to the advances in earlier detection and treatment, as well as in supportive care. Thus, the risk of second primary cancers after a BC has become clinically more relevant. Second primary malignancies may reflect several factors such as an increased surveillance that can lead to an overdiagnosis, a previous received therapy being the cause of the second malignancy, and shared genetic or environmental risk factors between the first and second cancer [6,20].

This study confirms the existence of an excess of GM following the diagnosis of BC. Globally, we observed 117 second GM with a statistically significant high SIR $(52 \%$ increased risk) which is caused by a high SIR in corpus uteri cancer (128\% increased risk). Approximately, 5.41 extra cases of GM per 100,000 women per year occurred among women who suffered BC.

Previous studies have suggested that women with a BC history have an elevated risk of developing a second $\operatorname{GM}(5,7)$. In a cohort of 9,729 BC Swiss patients followed from 1974 until 1998, Levy et al found greater risk of developing a second corpus uteri cancer and a second ovarian cancer (SIR 1.47 95\% CI 1.09-1.94 and SIR 1.26 95\% CI 0.85-1.79 respectively), but a lower risk of cervical cancer (SIR 0.52 95\% CI 0.21-1.06) [21]. Soerjomataram et al. found a $40 \%$ increased risk of developing a second corpus uteri cancer and a $70 \%$ increased risk of an ovarian cancer based on 9,919 BC Dutch patients over a period of 28 years (1972-2000). Further, they also observed a decrease by $10 \%$ of the cervical cancer risk among these patients [14]. One of the most important reports in number of patients $(525,527)$ and follow-up period $(1943-2000)$ was published by Mellemkjaer, et al. [11]. They included women from several countries with primary BC identified from 13 population-based cancer registries. They also found an excess risk of endometrial and ovarian cancers (SIR 1.52 and SIR 1.48 respectively) and a lower risk of cervical cancer (SIR 0.94). Other studies obtained statistically significant higher SIRs of corpus uteri cancer and ovarian cancer in Slovenia [12], Connecticut [13], Turkey [15] and other geographical areas. On the other hand, some studies have described an elevated risk also for cervical cancer. In 1997, Volk and Pompe-Kirn, in a Slovenian cohort of 8,917 BC patients diagnosed between 1961 and 1985 and followed-up to the end of 1994, found an increased risk of corpus uteri cancer (60\%), and ovarian $(130 \%)$ and cervical cancers (10\%) [12]. Differences in the risk of cervical cancer can be explained by the different time and degree of implementation of screening programmes for this cancer.

In agreement with previous reports, the main finding of this analysis is the excess of corpus uteri cancer in women diagnosed with invasive BC. Endogenous hormones, a shared risk factor for both $\mathrm{BC}$ and corpus uteri cancer, and exogenous hormones, related with hormone therapy for BC, could explain this finding. In addition, this excess of risk could be 
also explained by a surveillance bias after the diagnosis of $\mathrm{BC}$ and by the tamoxifen treatment, since it is related with the development of endometrial hyperplasia and cancer [22].

Tamoxifen is a selective oestrogen receptor modulator. It has an anti-oestrogenic effect on breast tissue and an oestrogenic (carcinogenic) effect in the endometrium, resulting in the development of atrophy, hyperplasia, polypus and endometrial carcinoma [23]. It has been widely used during the last 40 years as adjuvant treatment in $\mathrm{BC}$, for both premenopausal and postmenopausal women. Incidence results of second endometrial cancers after a long-term follow-up in studies on adjuvant hormonal therapy have been reported in the literature [17,24]. Multiple epidemiological studies and randomized prospective trials have shown an increased risk of endometrial cancer in association with prolonged tamoxifen treatment, with relative risks ranging from 2.53 to 7.5. It was also stated that there is an increased risk of developing uterine cancer among women receiving tamoxifen [25]. This finding has led to a major surveillance of these patients. Guidelines recommend surveillance with ultrasonography for patients receiving tamoxifen, despite its known low efficiency. There is also a strong recommendation to conduct a study with endometrial samples in patients who experience bleeding [26]. Recent result updates of one of the largest trials about adjuvant hormone therapy comparing 10 with 5 years of adjuvant tamoxifen (ATLAS trial) have been reported where an increase of the cumulative risk of endometrial cancer and specific mortality in postmenopausal women treated with tamoxifen has been found [24].

We detected a slight increase of unfavourable corpus uteri cancer histologies compared to those of the general population. An increased incidence of more aggressive histologies such as sarcomas has also been reported. In some case series, tamoxifen has been related to more aggressive histologies of corpus uteri cancer, such as uterine sarcoma [27] and high-grade uterine carcinoma [28]. More recently, a case-control study with 813 patients who developed endometrial cancer after a BC diagnosis showed an increased risk of endometrial cancer after treatment with tamoxifen for both premenopausal and postmenopausal women, which was statistically significant during and until 5 years after completing the treatment [29]. Another case series of 363 endometrial cancer patients showed that patients who develop an endometrial cancer after BC diagnosis showed worst prognostic, especially those who received tamoxifen, compared to patients without past medical history of BC [22]. In contrast, another recent report on the final results of the ATLAS trial showed higher cumulative risk of endometrial cancer, increasing with the treatment period length but outweighed by the risk of breast cancer mortality in hormone receptor positive patients [24].

Regarding ovarian cancer, in contrast to previous reports, our study found a non-statistically significant SIR $(0.96 ; 95 \% \mathrm{CI}$ $0.57-1.49$ ). However, these other studies found a trend for an increased incidence of ovarian cancer which can be explained by shared inherited susceptibility genes such as BRCA1 and $B R C A 2$ [9]. Both cancers are related, but only significantly in this order, ovary after breast, and not the other way around [8].

Even though the number of observed cases of cervical cancer is limited, our results are consistent with previous studies, showing a decreased risk among BC patients. This lower risk may be explained by the introduction of the cervical cancer screening programme in our National Health Service in 1993, routinely performed in patients with breast cancer who are under the surveillance of gynaecological teams [30].

The strengths of our study are the population-based design based on data of a cancer registry, and the large and complete follow-up of patients. Cancer registries are the only tool to assess the risk of second malignancies due to its completeness and follow-up of all patients.

The limitations are the lack of information about risk factors and received treatments, which could allow us to study their relations with the development of second tumours in our cohort, as well as data on the patients who had undergone oophorectomy or hysterectomy for other reasons. This information is usually not recorded in cancer registries.

Some gynaecological cancers, such as the vulvar and vaginal ones, and those registered as unspecified, such as primary Fallopian tube cancer, are rare. This fact, together with the lack of individual data on risk factors and treatments, makes it difficult to estimate how much of the excess risk might be associated with shared lifestyle or genetic factors, and how much could be related to the received treatment for the initial BC. The excess of risk could also be explained, as mentioned before, by the increased surveillance of these patients or their general susceptibility to cancer.

\section{Conclusion}

In conclusion, our results found that women already diagnosed with invasive $\mathrm{BC}$ have an increased risk of developing a second primary corpus uteri cancer compared to the general population, with a slight increase in histologies of worse prognosis. Lifelong primary and secondary prevention interventions should also be recommended for these patients. More detailed investigation on the risk factors related to these findings and its implication to $\mathrm{BC}$ patients' survival is warranted.

\section{Ethic Aspects}

This is a descriptive study based on anonymised data collected by the GCR. Informed consent was not requested because no work was performed with medical records or biological samples.

\section{Acknownledgement}

The authors thank Cristina Miracle for her comments on the manuscript. 


\section{References}

1. Bray F, Ferlay J, Soerjomataram I, Siegel RL, Torre LA, et al. Global Cancer Statistics 2018: GLOBOCAN Estimates of Incidence and Mortality Worldwide for 36 Cancers in 185 Countries. CA Cancer J Clin. 2018; 68: 394-424.

PubMed: https://www.ncbi.nlm.nih.gov/pubmed/30207593

2. Clèries $R$, Ameijide $A$, Marcos-Gragera $R$, Pareja $L$, Carulla $M$, et al Predicting the cancer burden in Catalonia between 2015 and 2025: the challenge of cancer management in the elderly. Clin Transl Oncol. 2018; 20: 647-657.

PubMed: https://www.ncbi.nlm.nih.gov/pubmed/29027110 surveillance of trends in cancer survival 2000-14 (CONCORD-3): analysis of individual records for 37513025 patients diagnosed with one of 18 cancers from 322 population-based registries in 71 countries. Lancet (London, England). 2018; 391: 1023-1075.

PubMed: https://www.ncbi.nlm.nih.gov/pubmed/29395269

4. Pollán $\mathrm{M}$, Pastor-Barriuso $\mathrm{R}$, Ardanaz $\mathrm{E}$, Argüelles $\mathrm{M}$, Martos $\mathrm{C}$, et al Recent changes in breast cancer incidence in Spain, 1980-2004. J Nat Cancer Inst. 2009; 101: 1584-1591.

PubMed: https://www.ncbi.nlm.nih.gov/pubmed/19861303

5. Matesich SMA, Shapiro CL. Second cancers after breast cancer treatment. Semin Oncol. 2003; 30: 740-748.

PubMed: https://www.ncbi.nlm.nih.gov/pubmed/14663775

6. Liu J, Jiang W, Mao K, An Y, Su F, et al. Elevated risks of subsequent endometrial cancer development among breast cancer survivors with different hormone receptor status: a SEER analysis. Breast Cancer Res Treat. 2015; 150: 439-445

PubMed: https://www.ncbi.nlm.nih.gov/pubmed/25764167

7. Demark-Wahnefried W, Aziz NM, Rowland JH, Pinto BM. Riding the crest of the teachable moment: Promoting long-term health after the diagnosis of cancer. J Clin Oncol. 2005; 23: 5814-5830.

PubMed: https://www.ncbi.nlm.nih.gov/pubmed/16043830

8. Suris-Swartz PJ, Schildkraut JM, Vine MF, Hertz-Picciotto I. Age at diagnosis and multiple primary cancers of the breast and ovary. Breast Cancer Res Treat. 1996; 41: 21-29.

PubMed: https://www.ncbi.nlm.nih.gov/pubmed/8932873

9. Stratton JF, Gayther SA, Russell P, Dearden J,Gore M, etal. Contribution of BRCA1 mutations to ovarian cancer. NEngl JMed. 1997;336:1125-1130. PubMed: https://www.ncbi.nlm.nih.gov/pubmed/9099656

10. Nagy E, Gajjar KB, Patel II, Taylor S, Martin-Hirsch PL, et al. MGMT promoter hypermethylation and K-RAS, PTEN and TP53 mutations in tamoxifen-exposed and non-exposed endometrial cancer cases. $\mathrm{Br} \mathrm{J}$ Cancer. 2014; 110: 2874-2880.

PubMed: https://www.ncbi.nlm.nih.gov/pubmed/24853176

11. Mellemkjær L, Friis S, Olsen JH, Scélo G, Hemminki K, et al. Risk of second cancer among women with breast cancer. Int J Cancer. 2006; 118: 2285-2292.

PubMed: https://www.ncbi.nlm.nih.gov/pubmed/16342146

12. Volk N, Pompe-Kirn V. Second primary cancers in breast cancer patients in Slovenia. Cancer Causes Control. 1997; 8: 764-770. PubMed: https://www.ncbi.nlm.nih.gov/pubmed/9328199

13. Harvey EB, Brinton LA. Second cancer following cancer of the breast in Connecticut, 1935-82. Natl Cancer Inst Monogr. 1985; 68: 99-112. PubMed: https://www.ncbi.nlm.nih.gov/pubmed/4088315

14. SoerjomataramI,LouwmanWJ,DeVriesE,Lemmens VEPP,KlokmanWJ, et al. Primary malignancy after primary female breast cancer in the south of the Netherlands, 1972-2001. BreastCancerRes Treat. 2005;93:91-95. PubMed: https://www.ncbi.nlm.nih.gov/pubmed/16184464

15. Gulhan I, Eser S, Yakut C, Bige O, Ilhan E, et al. Second primary gynecologic cancers after breast cancer in Turkish women. Int $\mathrm{J}$
Gynecol Cancer. 2009; 19: 648-650.

PubMed: https://www.ncbi.nlm.nih.gov/pubmed/19509564

16. Molina-Montes E, Pollán M, Payer T, Molina E, Dávila-Arias C, et al. Risk of second primary cancer among women with breast cancer: A populationbased study in Granada (Spain). Gynecol Oncol. 2013; 130: 340-345. PubMed: https://www.ncbi.nlm.nih.gov/pubmed/23648471

17. Jones ME, van Leeuwen FE, Hoogendoorn WE, Mourits MJE, Hollema $\mathrm{H}$, et al. Endometrial cancer survival after breast cancer in relation to tamoxifen treatment: Pooled results from three countries. Breast Cancer Res. 2012; 14: R91.

PubMed: https://www.ncbi.nlm.nih.gov/pubmed/22691381

18. Hall HI, Jamison $\mathrm{P}$, Weir HK. Second primary ovarian cancer among women diagnosed previously with cancer. Cancer Epidemiol Biomarkers Prev. 2001; 10: 995-999.

PubMed: https://www.ncbi.nlm.nih.gov/pubmed/11535553

19. Setiawan VW, Yang HP, Pike MC, McCann SE, Yu H, et al. Type I and II endometrial cancers: Have they different risk factors? J Clin Oncol. 2013; 31: 2607-2618.

PubMed: https://www.ncbi.nlm.nih.gov/pubmed/23733771

20. Dong C, Chen L. Second malignancies after breast cancer: The impact of adjuvant therapy. Mol Clin Oncol. 2014; 2: 331-336. PubMed: https://www.ncbi.nlm.nih.gov/pmc/articles/PMC3999127/

21. Levi F, Randimbison L, Te VC, La Vecchia C. Prognosis of bilateral synchronousbreastcancerin Vaud, Switzerland. Breast. 2003;12:89-91. PubMed: https://www.ncbi.nlm.nih.gov/pubmed/14659336

22. Ngô C, Brugier C, Plancher C, De La Rochefordière A, Alran S, et al. Clinicopathology and prognosis of endometrial cancer in patients previously treated for breast cancer, with or without tamoxifen: A comparative study in 363 patients. Eur J Surg Oncol. 2014; 40: 1237-1244. PubMed: https://www.ncbi.nlm.nih.gov/pubmed/25086993

23. Cohen I. Endometrial pathologies associated with postmenopausal tamoxifen treatment. Gynecol Oncol. 2004; 94: 256-266. PubMed: https://www.ncbi.nlm.nih.gov/pubmed/15297160

24. Davies C, Pan H, Godwin J, Gray R, Arriagada R, et al. Long-term effects of continuing adjuvant tamoxifen to 10 years versus stopping at 5 years after diagnosis of oestrogen receptor-positive breast cancer: ATLAS, a randomised trial. Lancet. 2013; 381: 805-816. PubMed: https://www.ncbi.nlm.nih.gov/pubmed/23219286

25. Van Leeuwen FE, Benraadt J, Coebergh JW, Kiemeney LA, Gimbrere $\mathrm{CH}$, et al. Risk of endometrial cancer after tamoxifen treatment of breast cancer. Lancet. 1994; 343: 448-452.

PubMed: https://www.ncbi.nlm.nih.gov/pubmed/7905955

26. Salani R, Andersen BL. Gynecologic care for breast cancer survivors: Assisting in the transition to wellness. Am J Obstet Gynecol. 2012; 206: 390-397. PubMed: https://www.ncbi.nlm.nih.gov/pubmed/22177185

27. Wickerham DL, Fisher B, Wolmark N, Bryant J, Costantino J, et al. Association of tamoxifen and uterine sarcoma. J Clin Oncol. 2002; 20 : 2758-2760.

PubMed: https://www.ncbi.nlm.nih.gov/pubmed/12039943

28. Magriples U, Naftolin F, Schwartz PE, Carcangiu ML. High-grade endometrial carcinoma in tamoxifen-treated breast cancer patients. $J$ Clin Oncol. 1993; 11: 485-490.

PubMed: https://www.ncbi.nlm.nih.gov/pubmed/8383191

29. Swerdlow AJ, Jones ME. Tamoxifen treatment for breast cancer and risk of endometrial cancer: a case-control study. J Natl Cancer Inst. 2005; 97: 375-384. PubMed: https://www.ncbi.nlm.nih.gov/ pubmed/15741574

30. Ascunze Elizaga N, González Enríquez J, González Navarro A, Herranz Fernández C, Marqués Bravo A, et al. Criterios generales y recomendaciones para la elaboracion de programas de deteccion precoz de cáncer de mama y cáncer de cérvix uterino en España. Rev San Hig Púb. 1993; 67: 23-37. 